\title{
Respiratory symptoms questionnaire for asthma epidemiology: validity and reproducibility
}

\author{
K M Venables, N Farrer, L Sharp, B J Graneek, A J Newman Taylor
}

\begin{abstract}
Background There is a need for a new respiratory symptoms questionnaire for use in epidemiological research in asthma.
\end{abstract}

Method A questionnaire was designed following a pilot study in 78 subjects. It contains nine questions on symptoms such as wheeze and difficulty with breathing in defined circumstances such as exercise and sleep. It was completed by 211 adults and validated by comparison with a self reported history of asthma and with bronchial hyperresponsiveness to histamine. Its short term reproducibility was measured by three repeat administrations over two weeks.

Results Subjects with asthma ( $=33$ ), particularly those having had an asthma attack in the last year $(n=23)$, were more likely to report any symptom and to report a greater number of symptoms than those without asthma. The same relationship was found for bronchial hyperresponsiveness and symptoms. Either two or more, or three or more, symptoms appeared to be good indices of self reported asthma and bronchial hyperresponsiveness, or both, with a high sensitivity (65-91\%) and specificity (85-96\%). Reproducibility was good, with few subjects changing the number of symptoms reported by more than one symptom and none by more than four symptoms. The results compared favourably with those from questions on phlegm production from the MRC questionnaire and were better than those reported for the MRC wheeze questions. Conclusions The questionnaire will be useful for epidemiological research on asthma and could form part of a new standardised questionnaire with wide applications.

(Thorax 1993;48:214-219)

Occupational an

Environmental

Medicine, National

Heart and Lung

Institute, Emmanuel

Kaye Building,

Manresa Road,

London SW3 6LR

$\mathrm{K} M$ Venables

N Farrer

L Sharp

B J Graneek

A J Newman Taylor

Reprint requests to:

Dr K M Venables

Received 22 February 1990

Accepted 7 December 1992

Respiratory symptoms questionnaires have wide application in epidemiological research on asthma, in particular in large surveys or longitudinal surveys, where it may not be practicable to perform physiological tests on all subjects. There is no generally accepted validated questionnaire for asthma research comparable to the MRC respiratory symptoms questionnaire ${ }^{1}$ and its revisions and variants. The MRC questionnaire was developed for research on chronic bronchitis, not asthma, and recent studies have shown its questions on wheeze to be specific but insensitive for measures of bronchial hyperresponsiveness, a typical feature of asthma. ${ }^{2-4}$ One study recommended that "priority should be placed upon designing and validating an asthma questionnaire." 4 We have designed a new questionnaire and report the relationship of answers to it to a history of asthma and to bronchial responsiveness to inhaled histamine, and have investigated its short term reproducibility.

\section{Methods}

Two hundred and eleven consecutive office workers from a central London office building were each studied three times during two weeks in January 1988. On the first study day, subjects answered a questionnaire about past medical history, smoking, and current respiratory symptoms. It was self administered and then checked for completeness. On the second and third study days they completed a similar but shorter questionnaire on current respiratory symptoms and on changes in health since the last study day.

The new respiratory symptoms questionnaire consisted of nine questions that had formed part of a 32 item pilot questionnaire, which had been tested in 78 subjects. Questions in the pilot questionnaire on symptoms in cold weather were excluded because of their limited application in longitudinal studies or in warm climates. The nine questions found in the pilot study to be best at detecting bronchial hyperresponsiveness were then selected. The questions were:

Current health (during the last four weeks):

1. If you run, or climb stairs fast do you ever cough?

wheeze?

get tight in the chest?

2. Is your sleep ever broken by wheeze? difficulty with breathing?

YES NO

YES NO

YES NO

YES NO

YES NO

3. Do you ever wake up in the morning (or from your sleep if a shift worker) with

\section{Do you ever wheeze if you are in a smoky room? YES NO if you are in a very dusty place? YES NO}

A history of asthma was obtained from the first questionnaire by the question "Have you 
ever had, or been told that you have had asthma?". Inquiry about the date of the last attack was made by the question: "If Yes, when did you last have it?"

On each study day a single blind histamine or saline (placebo) inhalation test was carried out after the questionnaire. Alternate subjects had tests in the order saline, histamine, histamine and the others in the order histamine, histamine, saline, performed by the method described by Yan et al. ${ }^{6}$ The placebo inhalation test with normal saline was carried with the same protocol as for the histamine test.

Calibrated leak free Vitalograph spirometers were used to record forced expiratory volume in one second $\left(\mathrm{FEV}_{1}\right)$. After inhalation of normal saline, quadrupling doses of histamine were inhaled from $0.06 \mu \mathrm{mol}$ to 4 $\mu \mathrm{mol}$ unless $\mathrm{FEV}_{1}$ fell by $10 \%$ or more of the value after saline, when doubling doses were given, or unless $\mathrm{FEV}_{1}$ fell by $20 \%$ or more, when no further doses were given. Subjects with a history of asthma, taking bronchodilator medication, with current respiratory symptoms, or whose $\mathrm{FEV}_{1}$ was $1.65 \mathrm{SD}$ or more below that expected for age, sex, and height $^{7}$ were tested with doubling doses starting at $0.03 \mu \mathrm{mol}$. One subject whose $\mathrm{FEV}_{1}$ was less than 1 litre was not tested.

The dose provoking a $20 \%$ fall in $\mathrm{FEV}_{1}$ $\left(\mathrm{PD}_{20}\right)$ was estimated by linear interpolation of the last two log dose points or by extrapolation up to $8 \mu \mathrm{mol}$. Subjects whose $\mathrm{PD}_{20}$ was $8 \mu \mathrm{mol}$ or less in either histamine test were regarded as having bronchial hyperresponsiveness. In the calculation of mean $\mathrm{PD}_{20}$ for these hyperresponsive subjects, if $\mathrm{PD}_{20}$ was not measurable in one of the two tests that test was assigned a value of $8 \mu \mathrm{mol}$.

Subjects always saw the same investigator (of four) and, as far as possible, were assessed at the same time on each study day. They were asked not to use inhalers for "the chest or breathing" for six hours before the appointment unless the treatment was necessary. Each subject was a volunteer and received written and verbal explanations of the procedures. The study was approved by the Royal Brompton Hospital Ethical Committee.
The sensitivity, specificity, and positive predictive value of the questionnaire were calculated conventionally against three criteria: a history of asthma in the last year, bronchial hyperresponsiveness, and either of the two:

\begin{tabular}{llll} 
& & \multicolumn{3}{c}{ Criterion } \\
& & + & - \\
Symptoms & + & $\mathrm{a}$ & $\mathrm{b}$ \\
& - & $\mathrm{c}$ & $\mathrm{d}$
\end{tabular}

where sensitivity $=a /(a+c)$, specificity $=d$ / $(b+d)$, positive predictive value $=a /(a+b)$

The reproducibility of the questionnaire was assessed by administering it on each of the three study days. Agreement and repeatability were used as indices of reproducibility:

\section{Symptoms 2}

$\begin{array}{llll} & + & - \\ \text { Symptoms } 1+ & \mathrm{a} & \mathrm{b} \\ & - & \mathrm{c} & \mathrm{d}\end{array}$

defining agreement as $(a+d) /(a+b+c+d)$ and repeatability as $a /(a+b+c)$. These indices were calculated separately for day 1 against day 2, and for day 2 against day 3 .

Statistical analysis was carried out by means of $\chi^{2}$ tests for heterogeneity and trend and by calculation of Spearman's rank correlation coefficient, taking $p \leqslant 0.05$ to be significant.

\section{Results}

Of the 211 subjects, 206 had two histamine inhalation tests and 204 attended on all three study days. The group contained 75 men and 136 women and its mean (SD) age was $39 \cdot 1$ $(12 \cdot 7)$ years. Forty one of $211(19 \%)$ currently smoked, 44 (21\%) were exsmokers, and $126(60 \%)$ had never smoked.

The subjects had no difficulties in understanding and answering the nine respiratory symptoms questions. On study day 1, 125 of the 211 subjects (59\%) reported no symptoms, $86(41 \%)$ had at least one symptom and $33(16 \%)$ at least three (table 1). Age, gender, and smoking habit did not differ significantly by number of symptoms (table 2), nor was number of symptoms related to the day, time of appointment, or the investigator.

Table 1 Relationship of number of symptoms in the new questionnaire to history of asthma

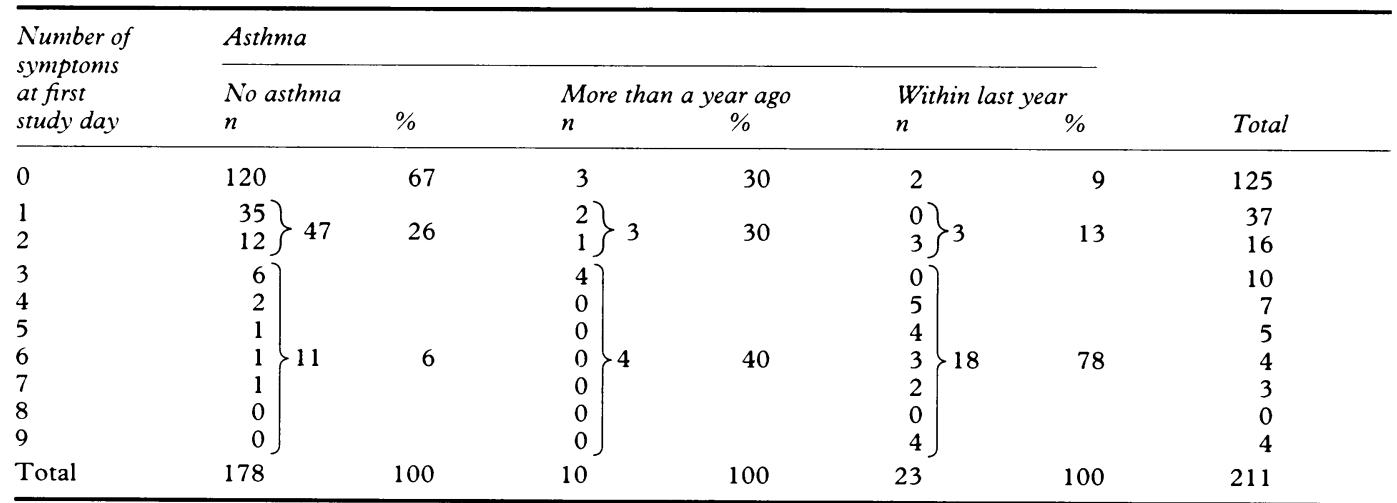

To increase expected numbers for $\chi^{2}$ tests, those with asthma more than a year ago were grouped with those with no asthma and row groupings were as indicated by brackets: $\chi^{2}$ for heterogeneity $=77 \cdot 36(p \leqslant 0 \cdot 001) ; \chi^{2}$ for trend $=59 \cdot 14(p \leqslant 0 \cdot 001)$ 
Table 2 Characteristics of subjects by number of symptoms in the new questionnaire

\begin{tabular}{llll}
\hline & \multicolumn{4}{l}{ Number of symptoms } \\
\cline { 2 - 4 } & $\begin{array}{l}0 \\
(n=125)\end{array}$ & $\begin{array}{l}1-2 \\
(n=53)\end{array}$ & $\begin{array}{l}3-9 \\
(n=33)\end{array}$ \\
\hline $\begin{array}{lll}\text { Mean (SD) age (years) } \\
\% \text { male }\end{array}$ & $39 \cdot 2(12 \cdot 4)$ & $40 \cdot 0(12 \cdot 9)$ & $\begin{array}{l}37 \cdot 1(13 \cdot 9) \\
\% \text { ever (current) smoker }\end{array}$ \\
\hline
\end{tabular}

Table 3 Relationship of history of asthma to bronchial hyperresponsiveness

\begin{tabular}{|c|c|c|c|c|c|}
\hline \multirow{3}{*}{$\begin{array}{l}\text { History of } \\
\text { asthma }\end{array}$} & \multicolumn{4}{|c|}{ Histamine $P D_{20}$} & \multirow[b]{3}{*}{ Total } \\
\hline & \multicolumn{2}{|c|}{ More than $8 \mu \mathrm{mol}$} & \multicolumn{2}{|c|}{$8 \mu \mathrm{mol}$ or less } & \\
\hline & $n$ & $\%$ & $n$ & $\%$ & \\
\hline \multirow{3}{*}{\multicolumn{6}{|c|}{$\begin{array}{l}\text { No asthma } \\
\text { Asthma more than } \\
\text { a year ago }\end{array}$}} \\
\hline & & & & & \\
\hline & 3 & 2 & 7 & 24 & 10 \\
\hline \multicolumn{6}{|l|}{ Asthma within last } \\
\hline year & 8 & 5 & 13 & 45 & 21 \\
\hline Total & 177 & 100 & 29 & 100 & 206 \\
\hline
\end{tabular}

$\chi^{2}=77 \cdot 12(p \leqslant 0 \cdot 001)$.

Table 4 Relationship of number of symptoms in the new questionnaire with bronchial hyperresponsiveness

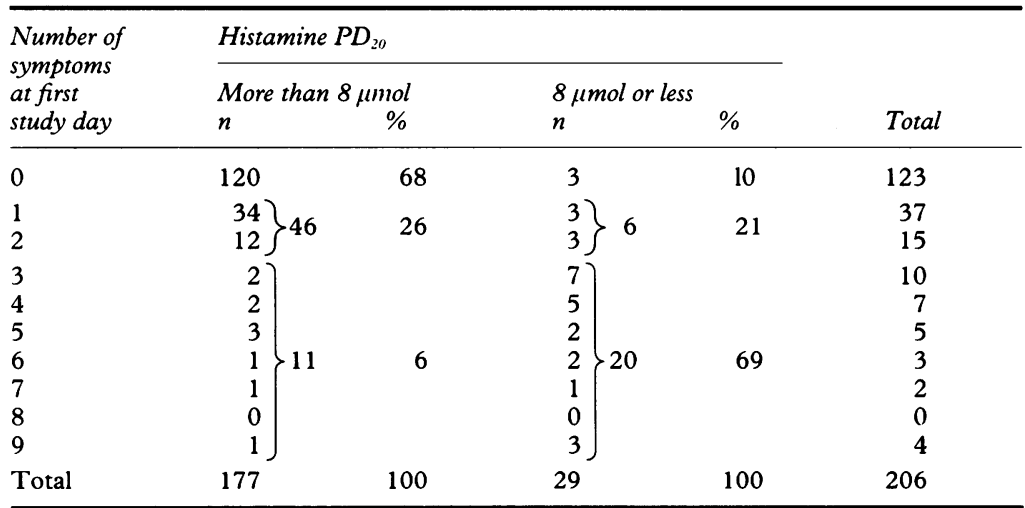

Grouping rows as indicated by brackets: $\chi^{2}$ for heterogeneity $=79.25(p=0.001) ; \chi^{2}$ for trend $=21.07(\mathrm{p}=0.001)$
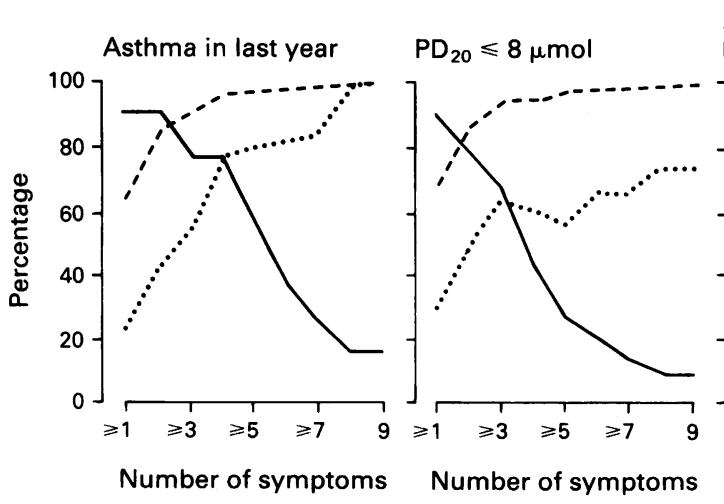

Asthma in last year or $\mathrm{PD}_{20} \leqslant 8 \mu \mathrm{mol}$

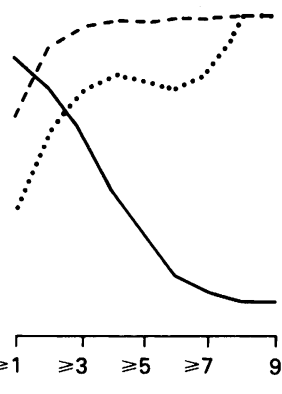

Figure 1 Sensitivity (-), specificity (-- ), and positive predictive value (...) of symptoms in the new questionnaire for a history of asthma in the last year, $P D_{20}$ of $8 \mu \mathrm{mol}$ or less, or either. Increasing numbers of symptoms were used as cut off values for a "positive" questionnaire (one or more symptoms, two or more symptoms, and so on up to nine symptoms).
SYMPTOMS AND SELF REPORTED ASTHMA

Thirty three subjects $(16 \%)$ reported a history of asthma, and $23(11 \%)$ had had an attack in the last year. Of these 23, 21 reported symptoms in the new questionnaire, compared with seven of 10 who last had an attack more than a year ago and one third of those who denied a history of asthma (table 1). The prevalence of a report of asthma in the last year showed a significant trend with increasing number of symptoms reported in the new questionnaire (table 1): 18 of 33 (55\%) with three or more symptoms had had asthma in the last year, three of $53(6 \%)$ with one or two symptoms, and two of $125(2 \%)$ with no symptoms.

\section{SYMPTOMS AND PD $_{20}$}

Twenty nine $(14 \%)$ of 206 subjects who had two histamine inhalation tests had a $\mathrm{PD}_{20}$ of $8 \mu \mathrm{mol}$ or less in one or both tests, $23(11 \%)$ in the first test, $22(11 \%)$ in the second test and $16(8 \%)$ in both tests. The $95 \%$ range for a single estimate ${ }^{89}$ was \pm 1.6 doubling doses, and was $\pm 1 \cdot 1$ doubling doses considering only the 16 with a $\mathrm{PD}_{20}$ of $8 \mu \mathrm{mol}$ or less in both tests. A self reported history of asthma was significantly related to bronchial hyperresponsiveness (table 3 ).

The relationship between number of symptoms in the new questionnaire and bronchial hyperresponsiveness (table 4) was similar to that for number of symptoms and asthma (table 1): those with a $\mathrm{PD}_{20}$ of $8 \mu \mathrm{mol}$ or less were more likely to report symptoms and reported a greater number of symptoms than those without a measurable $\mathrm{PD}_{20}$. As number of symptoms increased, mean $\mathrm{PD}_{20}$ fell $\left(r_{\mathrm{s}}=\right.$ $-0 \cdot 25)$ and was not statistically significant. There was also a weak relationship in the expected direction between number of symptoms and mean change in $\mathrm{FEV}_{1}$ at the final dose of histamine in 177 subjects without a measurable $\mathrm{PD}_{20}\left(r_{\mathrm{S}}=+0 \cdot 13\right)$.

The sensitivity, specificity, and positive predictive value of questionnaire symptoms for a history of asthma in the last year, for bronchial hyperresponsiveness, and for both, are shown in fig 1. Specificity and positive predictive value increased with number of symptoms and sensitivity fell.

\section{REPRODUCIBILITY}

The 204 subjects who attended on all three study days were included in reproducibility analyses. The prevalence of at least one symptom in the new questionnaire fell slightly from the first $(82,40 \%)$ to the second study day $(76,37 \%)$ and did not change between the second and third days $(75,37 \%)$. Of 84 who reported symptom(s) in questionnaires on the first or second study days, $50(60 \%)$ had the same number of symptoms on both days, $26(31 \%)$ had fewer on the second day, and eight $(10 \%)$ had more; the corresponding figures for the comparison between the second and third study days based on 78 with symptom(s) were $58(74 \%), 12(15 \%)$ and eight $(10 \%)$ (table 5 ). No subject changed the number of symptoms by more than four 
Table 5 Comparison of number of symptoms in the new questionnaire on the three study days

\begin{tabular}{|c|c|c|c|c|c|c|c|c|c|c|c|c|c|c|c|c|c|c|c|c|}
\hline \multicolumn{10}{|c|}{ Study days 1 and 2} & \multicolumn{11}{|c|}{ Study days 2 and 3} \\
\hline \multirow[t]{2}{*}{ Day 1} & \multirow[b]{2}{*}{1} & \multirow[b]{2}{*}{2} & \multirow[b]{2}{*}{3} & \multicolumn{2}{|c|}{ Day 2} & \multirow[b]{2}{*}{6} & \multirow[b]{2}{*}{7} & \multirow[b]{2}{*}{8} & \multirow[b]{2}{*}{9} & \multirow[t]{2}{*}{ Day 2} & \multirow[b]{2}{*}{0} & \multirow[b]{2}{*}{1} & \multirow[b]{2}{*}{2} & \multirow[b]{2}{*}{3} & \multicolumn{2}{|c|}{ Day 3} & \multirow[b]{2}{*}{6} & \multirow[b]{2}{*}{7} & \multirow[b]{2}{*}{8} & \multirow[b]{2}{*}{9} \\
\hline & & & & 4 & 5 & & & & & & & & & & 4 & 5 & & & & \\
\hline 120 & 1 & & 1 & & & & & & & 0 & 26 & 1 & & & 1 & & & & & \\
\hline 1 & 28 & 3 & & & & & & & & 1 & 2 & 33 & & & & & & & & \\
\hline 2 & 5 & 8 & & 1 & & & & & & 2 & & 3 & 9 & 4 & & & & & & \\
\hline 3 & 1 & 4 & 4 & 1 & & & & & & 3 & & & 2 & 7 & & & & 1 & & \\
\hline 4 & & 1 & 2 & 2 & 1 & & & & & 4 & 1 & & & 1 & 3 & & & & & \\
\hline 5 & & & 2 & & 3 & & & & & 5 & & & & 1 & 1 & 2 & & & & \\
\hline 6 & & & & & & 2 & & & & 6 & & & & & & 1 & 1 & & & \\
\hline 7 & & & 1 & 1 & & & & & & 7 & & & & & & & & & & \\
\hline 8 & & & & & & & & & & 8 & & & & & & & & & & 1 \\
\hline 9 & & & & & & & & 1 & 3 & 9 & & & & & & & & & & 3 \\
\hline $\begin{array}{l}\text { Number of } \\
\text { symptoms }\end{array}$ & & & $\begin{array}{l}\text { Agree } \\
(\%)\end{array}$ & ent & & & $\begin{array}{l}\text { Repe } \\
(\%)\end{array}$ & abil & & $\begin{array}{l}\text { Number } \\
\text { symptoms }\end{array}$ & & & & $\begin{array}{l}\text { Agre } \\
(\%)\end{array}$ & lent & & & $\begin{array}{l}\operatorname{Rep} \\
(\%)\end{array}$ & $a b$ & \\
\hline Same & & & 83 & & & & 60 & & & Same & & & & 90 & & & & 74 & & \\
\hline \pm 1 & & & 95 & & & & 88 & & & \pm 1 & & & & 98 & & & & 95 & & \\
\hline \pm 2 & & & 98 & & & & 95 & & & \pm 2 & & & & 99 & & & & 96 & & \\
\hline \pm 3 & & & 99 & & & & 98 & & & \pm 3 & & & & 99 & & & & 96 & & \\
\hline \pm 4 & & & 100 & & & & 100 & & & \pm 4 & & & & 100 & & & & 100 & & \\
\hline
\end{tabular}

Days 1 and 2

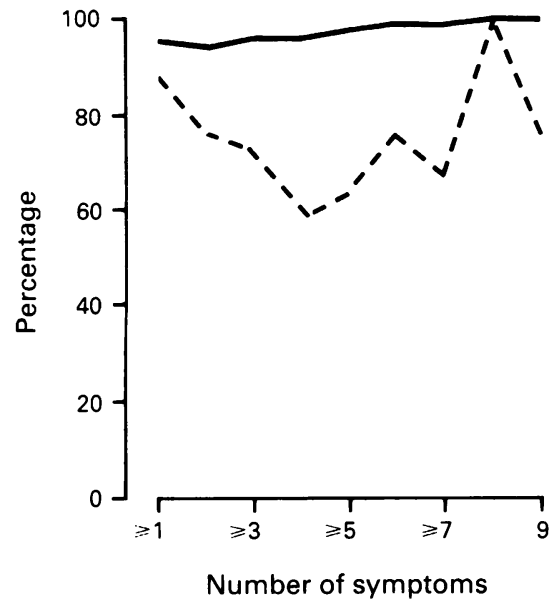

Days 2 and 3

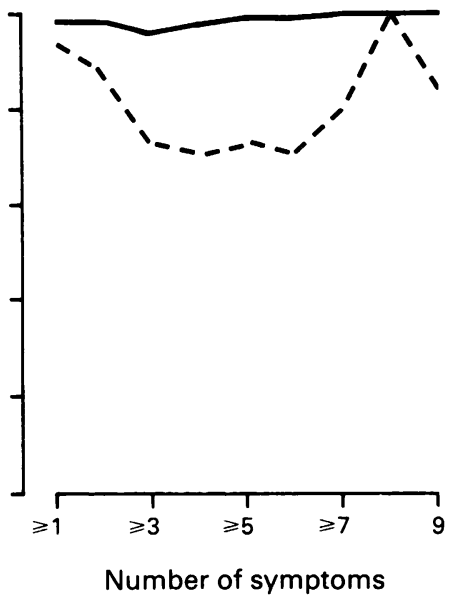

Figure 2 Agreement (-) and repeatability (--) of symptoms in the new questionnaire for two pairs of assessments by number of symptoms used to define a "positive" questionnaire (as in fig 1). The number of subjects with seven or more symptoms is small and estimates may not be reliable.

Table 6 Characteristics of subjects with symptoms by repeatability of number of symptoms in the new questionnaire

\begin{tabular}{|c|c|c|}
\hline & \multicolumn{2}{|c|}{ Difference in number of symptoms } \\
\hline & $\begin{array}{l}\text { None } \\
(n=44)\end{array}$ & $\begin{array}{l}\text { One or more } \\
(n=40)\end{array}$ \\
\hline $\begin{array}{l}\text { Mean }(\mathrm{SD}) \text { age (years) } \\
\% \text { male } \\
\% \text { ever (current) smoker } \\
\% \text { asthma in last year }\end{array}$ & $\begin{array}{l}37 \cdot 2(12 \cdot 6) \\
30 \\
45(23) \\
20\end{array}$ & $\begin{array}{l}41 \cdot 7(13 \cdot 6) \\
40 \\
45(20) \\
25\end{array}$ \\
\hline $\begin{array}{l}\mathrm{PD}_{211} \\
\% \text { measurable on one test only } \\
\% \text { measurable on both tests }\end{array}$ & $\begin{array}{r}2 \\
18\end{array}$ & $\begin{array}{l}25^{\star \star} \\
20\end{array}$ \\
\hline $\begin{array}{l}\text { Between study days: } \\
\% \text { reporting asthma, bronchitis } \\
\text { or hay fever } \\
\% \text { reporting allergen exposure }\end{array}$ & $\left.\begin{array}{l}2 \\
2\end{array}\right\} 2$ & $\left.\begin{array}{r}8 \\
15\end{array}\right\} 20^{\star}$ \\
\hline$\%$ reporting a cold or 'flu & 14 & 13 \\
\hline $\begin{array}{l}\text { Interval between study days: } \\
\% \text { more than a day, days } 1 \text { to } 2 \\
\% \text { more than a day, days } 2 \text { to } 3\end{array}$ & $\begin{array}{l}25 \\
43\end{array}$ & $\begin{array}{l}33 \\
43\end{array}$ \\
\hline
\end{tabular}

between pairs of study days. Most subjects remained within one symptom: $194(95 \%)$ for days 1 and 2 , and $200(98 \%)$ for days 2 and 3 (table 5). Expressing variability in number of symptoms as repeatability (see definition in Methods) gave lower, though still high, percentages: 74 of $84(88 \%)$ were within one symptom for days 1 and 2 , and 74 of $78(95 \%)$ for days 2 and 3 (table 5 ).

The agreement and repeatability of symptoms for the two pairs of study days by increasing number of symptoms are shown in fig 2. Agreement was consistently high. Repeatability fell from about $90 \%$ for one or more symptoms to about $60-75 \%$ for three or more.

Of 84 subjects with symptom(s) in the new questionnaire on at least one of the three study days, 40 changed the number of symptoms once or twice. Significantly more of these $\mathbf{4 0}$ gave a history of asthma, bronchitis, hay fever, or contact with an allergen which affected "chest, nose or breathing" between study days (table 6). Of these 40 , the $\mathrm{PD}_{20}$ changed from measurable to non-measurable (or vice versa) in $10(25 \%)$ during the study, but in only one $(2 \%)$ of the 44 whose number of symptoms did not change ( $p \leqslant 0.01$, table 6). A comparison of change in number of symptoms with change in $\mathrm{PD}_{20}$ (in doubling doses) was made for the 29 subjects with bronchial hyperresponsiveness. The relation was as predicted, with a fall in symptom number associated with a rise in $\mathrm{PD}_{20}$, but was weak and not statistically significant (day 1 to day $2 r_{\mathrm{s}}=-0.24$, day 2 to day $3 r_{\mathrm{s}}=$ $-0.08)$. Age, gender, smoking habit, history of asthma, and interval between study days did not differ significantly by whether the number of symptoms changed or not (table 6 ), nor did day or time of the first appointment, difference in time of appointments, or which investigator saw the subject. Four subjects did not change the number of symptoms but changed which symptom(s) they reported: there were no important differences if they were reclassified in the analysis. 


\section{Discussion}

There is no consensus on a single best test for asthma in epidemiological studies and it is likely that the choice will remain dependent on a study's aims and size. Some studies have relied on self reported history of asthma but this is influenced by doctors' diagnostic practices ${ }^{10}$ which may vary in time and place. Tests of non-specific bronchial responsiveness are objective, but practical considerations may preclude their use in large studies and hyperresponsiveness alone may be too narrow a definition of asthma for research purposes. ${ }^{11}$ Our findings confirm that hyperresponsiveness to histamine is related to a history of asthma: $45 \%$ of subjects with a $\mathrm{PD}_{20}$ of $8 \mu \mathrm{mol}$ or less gave a history of asthma in the last year but only $5 \%$ of those with a $\mathrm{PD}_{20}$ over $8 \mu \mathrm{mol}$. Similar figures of $50 \%$ and $4 \%$ have been obtained in another British study using the same inhalation test protocol. ${ }^{8}$ Our findings also confirm that the short term reproducibility of the inhalation test method originally described by Yan et $\mathrm{al}^{6}$ is adequate for epidemiological work and our results compare favourably with those obtained by others using the same method. ${ }^{89}$

The questionnaire compared well both with a history of asthma and with bronchial hyperresponsiveness, suggesting that it provides a valid index of asthma for epidemiological purposes. The symptoms were associated significantly with both a history of asthma and also bronchial hyperresponsiveness, and the prevalence of both increased significantly with number of symptoms. The relationship with number of symptoms suggests that subjects with asthma experience several related but distinguishable symptoms provoked by a variety of circumstances, which accords with clinical experience. The pilot study ${ }^{5}$ had predicted a rather better relationship between number of symptoms and $\mathbf{P D}_{20}$ than was found in this study, almost certainly because the pilot study had examined a larger number of symptoms and had used a higher dose of agonist which gave a wider range of $\mathrm{PD}_{20}$ values. The weak relationship implies that the questionnaire would not estimate the level of responsiveness with precision, although it could be used to assign subjects to broad classes.

The new questionnaire can be used to provide a dichotomous index of "symptoms of asthma". A report of one or more symptoms was highly sensitive for a history of asthma (91\%), bronchial hyperresponsiveness $(90 \%)$, or either $(86 \%)$, but was less specific (65-70\%) (fig 1), although such a sensitive index could have uses as a screening tool. Two or more, and three or more, symptoms gave increased specificity for a history of asthma $(85 \%$ and $92 \%)$, for bronchial hyperresponsiveness $(87 \%$ and $94 \%)$, and for either (90\% and $96 \%$ ) without unduly compromising sensitivity $(91 \%$ and $78 \%, 79 \%$ and $69 \%, 78 \%$ and $65 \%$ ). These values of sensitivity and specificity should be compared with those of a symptom question whose validity is generally accepted and we have chosen the questions on sputum production in the MRC questionnaire, ${ }^{12-14}$ which have been reviewed by Samet. ${ }^{15}$ The questions on sputum production, when compared with the presence of sputum in a collection bottle, had sensitivity values in the range $43-84 \%$ and specificity values in the range $75 \%$ or less to $91 \%$. Our study suggested a sensitivity of $65-91 \%$ and a specificity of $85-96 \%$, which compares favourably.

Our new questionnaire and two others which also ask about symptoms in defined circumstances are all more sensitive for bronchial hyperresponsiveness than the questions in the MRC questionnaire on wheeze..$^{2-4}$ Mortagy et al ${ }^{16}$ described a questionnaire about nocturnal or morning symptoms, or symptoms with environmental irritants. Combining data from their studies of 75 and 90 subjects, a report of at least one symptom in their questionnaire had a sensitivity of $35 \%$ and specificity of $95 \%$ for a histamine $\mathrm{PC}_{20}$ of less than $8 \mathrm{mg} / \mathrm{ml}$. These values are similar to those for four or five symptoms in our questionnaire which may suggest that our questionnaire is more sensitive for bronchial hyperresponsiveness, or may be explained by differences in inhalation test protocols. Burney et $a l^{17}$ used the same inhalation test protocol as in our study in 256 subjects to validate a discriminant function predictor derived from the International Union against Tuberculosis and Lung Disease (IUATLD) bronchial symptoms questionnaire. They obtained values of sensitivity (53\%) and specificity $(90 \%)$ which are intermediate between those in our study and that of Mortagy et al. ${ }^{16}$ The symptoms used to derive the discriminant function predictor included shortness of breath at night and tightness in the chest in dusty parts of the house or with animals or feathers. These broadly similar results from different investigators in different populations strengthen each other.

The predictive value of a questionnaire is an important measure but depends on the prevalence of asthma in the population under study, as well as on sensitivity and specificity. Our predictive value results can be generalised to the population as a whole because $14 \%$ had bronchial hyperresponsiveness which was identical to the prevalence reported by Burney et al ${ }^{18}$ using the same method in a population sample with the same age range as ours and also from the south of England. A history of asthma in the last year was reported in $11 \%$ of our population, and although we have no comparison figures for the question we used, this prevalence seems reasonable. Our questionnaire's positive predictive value would be greater in populations with a high prevalence of asthma such as some occupational groups. ${ }^{19}$

Number of symptoms was not significantly associated with age, gender, smoking habit, or variables related to the technical conduct of the study such as which investigator saw the subject. This suggests it may not be necessary to adjust for these variables when using the questionnaire, although further 
experience in its use is desirable before assuming this.

The short term reproducibility of the questionnaire was good. Measured as agreement, the reproducibility of two or more symptoms was $94 \%$ and $98 \%$ and of three or more symptoms was $96 \%$ and $96 \%$. This is similar to that for smoking habit ${ }^{15}$ and better than the $78-91 \%$ reported for phlegm production. ${ }^{12} 20-24$ Agreement is a widely used measure of reproducibility but has the drawback that it increases with decreasing prevalence of symptoms. Repeatability is a more stable estimate of reproducibility and the repeatability of this questionnaire was $76 \%$ and $88 \%$ for two or more symptoms, and $72 \%$ and $73 \%$ for three or more symptoms. This is better than the range of $38-71 \%$ reported for phlegm production. ${ }^{120-24}$

Our good results could be explained in part by the study's control of observer variation and its short test to retest interval. Repeatability generally increases as the test to retest interval falls, ${ }^{12} 20-24$ perhaps because subjects can remember previous answers more readily, but also because respiratory symptoms change less over days or weeks than they do over several months. It is important to use a short time interval in studying the reproducibility of tests intended to detect asthma because it is a condition of variable severity in which real changes occur over short periods. Our findings suggest that a change in number of symptoms in the new questionnaire of more than one or two is unusual and further suggest that change in number of symptoms reflects change in respiratory health or $\mathrm{PD}_{20}$ (table 6). Reproducibility was slightly better between the second and third study days than between the first and second, which may suggest that a practice session could be useful in longitudinal studies.

In conclusion we, in common with others, ${ }^{1617}$ have found that a questionnaire about respiratory symptoms in defined circumstances is a better predictor of asthma and bronchial hyperresponsiveness than the MRC wheeze questions. Our questionnaire has good short term reproducibility and may be a better discriminator of bronchial hyperresponsiveness than other questionnaires. ${ }^{16} 17$ Questionnaires for asthma epidemiology are now at the same stage as those for bronchitis research in the 1950s. We recommend that interested organisations such as the MRC and IUATLD should bring together the groups that are working on these questionnaires.

[Tables summarising published information on the validity and reproducibility of the questions on sputum production from the MRC questionnaire are available from the authors.]
We thank Miss Rosemarie Hawkins, Mr John Upton, Dr Paul Cullinan and Dr Ian Hughes Hallett and his staff for their help with the study. Mr Upton was supported by the Camilla Samuel Fund.

1 Medical Research Council Committee on the Aetiology of Chronic Bronchitis. Standardized questionaries on respiratory symptoms. BMF 1960;ii: 1665 .

2 Dales RE, Ernst P, Hanley JA, Battista RN, Becklake MR. Prediction of airway reactivity from responses to a standardised respiratory symptom questionnaire. $\mathrm{Am} R e v$ Respir Dis 1987;135:817-21.

3 Rijcken B, Schouten JP, Weiss ST, Speizer FE, van der Lende $R$. The relationship of non specific bronchial responsiveness to respiratory symptoms in a random population sample. Am Rev Respir Dis 1987;136:62-8.

4 Enarson DA, Vedal S, Schulzer M, Dybuncio A, ChanYeung M. Asthma, asthma like symptoms, chronic bronchitis, and the degree of bronchial hyperresponsiveness in epidemiologic surveys. Am Rev Respir Dis 1987;136:613-7.

5 Venables KM, Farrer NM, Graneek BJ, Newman Taylor AJ. Respiratory symptoms and the bronchial response to methacholine: a pilot study of a new questionnaire. $A m$ Rev Respir Dis 1988;137 (Suppl):A848 (abstract).

6 Yan K, Salome C, Woolcock AJ. Rapid method for measurement of bronchial responsiveness. Thorax 1983;38: $760-5$.

7 Cotes JE. Lung function: assessment and application in medicine. 4th edn. Oxford: Blackwell, 1979.

8 Chinn S, Britton JR, Burney PGJ, Tattersfield AE Papacosta AO. Estimation and repeatability of the response to inhaled histamine in a community survey. Thorax 1987;42:45-52.

9 Higgins BG, Britton JR, Chinn S, Jones TD, Vathenen AS, Burney PGJ, et al. Comparison of histamine and methacholine for use in bronchial challenge tests in community studies. Thorax $1988 ; 43: 605-10$.

10 Burrows B. The natural history of asthma. $\mathcal{f}$ Allergy Clin Immunol 1987;80:373-7.

11 Scadding JG. Asthma and bronchial reactivity. $B M Y$ 1987;294:1115-6.

12 Fletcher CM, Elmes PC, Fairbairn AS, Wood CH. The significance of respiratory symptoms and the diagnosis of chronic bronchitis in a working population. BMF of chronic bronch

13 van der Lende R, Orie NGM. The MRC-ECCS questionnaire on respiratory symptoms (use in epidemiology) Scand F Respir Dis 1972;53:218-26.

14 Fletcher CM, Richard P, Tinker CM. A comparison of the assessment of simple bronchitis (chronic mucus hypersecretion) by measurements of sputum volume and by standardized questions on phlegm production. Int $\mathcal{F}$ Epidemiol 1974;3:315-9.

15 Samet JM. Historical and epidemiologic perspective on respiratory symptoms questionnaires. $\mathrm{Am} \mathcal{F}$ Epidemiol 1978;108:435-46.

16 Mortagy AK, Howell JBL, Waters WE. Respiratory symptoms and bronchial reactivity: identification of a syndrome and its relation to asthma. BMF 1986;293:525-9.

17 Burney PJG, Chinn S, Britton JR, Tattersfield AE, Papacosta AO. What symptoms predict the bronchial response to histamine? Evaluation in a community survey of the bronchial symptoms questionnaire (1984) of the International Union against Tuberculosis and Lung the International Union against Tubercu
Disease. Int $f$ Epidemiol 1989;18:165-73.

18 Burney PGJ, Britton JR, Chinn S, Tattersfield AE Papacosta AO, Kelson MC, et al. Descriptive epidemiology of bronchial reactivity in an adult population: results from a community study. Thorax 1987;42:38-44.

19 Venables KM. Epidemiology and the prevention of occupational asthma. Br $\mathcal{F}$ Ind Med 1987;44:73-5.

20 Fletcher CM, Tinker CM. Chronic bronchitis: a further study of simple diagnostic methods in a working population. BMF 1961;i:1491-8.

21 Crooke Morgan D, Pasqual RSH, Ashford JR, Seasonal variations in the measurement of ventilatory capacity and in the answers of working coal miners to a respiratory symptoms questionary. $\mathrm{Br} \quad \mathcal{f}$ Prev $\mathrm{Soc} \mathrm{Med}$ 1964;18:88-97.

22 Holland WW, Ashford JR, Colley JRT, Crooke Morgan $D$, Pearson NJ. A comparison of two respiratory symptoms questionnaires. Br 7 Prev Soc Med 1966;20:76-96.

$23 \mathrm{McNab}$ GR, Slator EJ, Stewart CJ. Response to a questionnaire on chronic bronchitic symptoms in East Anglia. Br f Prev Soc Med 1966;20:181-8.

24 Lebowitz MD, Burrows B. Comparison of questionnaires: the BMRC and NHLI respiratory questionnaires and new self-completion questionnaire. Am Rev Respir Dis 1976;113:627-35. 